\title{
Repression by the $3^{\prime}$ UTR of fem-3, a sex-determining gene, relies on a ubiquitous mog-dependent control in Caenorhabditis elegans
}

\section{Maria Gallegos' ${ }^{1}$, Julie Ahringer ${ }^{2}$, Sarah Crittenden ${ }^{3}$ and Judith Kimble ${ }^{1,3,4,5}$}

\author{
${ }^{1}$ Program of Cellular and Molecular Biology, ${ }^{3}$ Howard Hughes \\ Medical Institute, ${ }^{4}$ Departments of Biochemistry and Medical Genetics \\ and Laboratory of Cell and Molecular Biology, University of \\ Wisconsin-Madison, 433 Babcock Drive, Room 341E, Madison, \\ WI 53706, USA and ${ }^{2}$ Wellcome CRC Institute, Tennis Court Road, \\ Cambridge CB2 1QR, UK \\ ${ }^{5}$ Corresponding author \\ e-mail: jekimble@facstaff.wisc.edu
}

The fem-3 sex-determining gene is repressed posttranscriptionally via a regulatory element in its $3^{\prime}$ untranslated region (UTR) to achieve the switch from spermatogenesis to oogenesis in the Caenorhabditis elegans hermaphrodite germ line. In this paper, we investigate the $f e m-33^{\prime}$ UTR control in somatic tissues using transgenic reporter assays, and we also identify six genes essential for this control. First, we find that a reporter transgene bearing a wild-type $f e m-33^{\prime}$ UTR is repressed in somatic tissues, whereas one bearing a mutant fem-3 $3^{\prime}$ UTR is derepressed. Moreover, control by mutant $3^{\prime}$ UTRs is temperature sensitive as predicted from the temperature sensitivity of the fem-3 gain-of-function ( $g$ f) mutations. Secondly, we find a fem-3 $3^{\prime}$ UTR RNA-binding activity in somatic tissues, in addition to the previously reported germline-specific binding by FBF. Thirdly, we find that each of six genes, mog-1-mog-6, is required for repression by the fem-3 $3^{\prime}$ UTR. Therefore, the mog genes not only affect the sperm/oocyte switch in the germ line, but also function in somatic tissues. We suggest that the mog genes may encode components of a ubiquitous machinery that is used for fem-3 $3^{\prime}$ UTR-mediated repression and the sperm/oocyte switch.

Keywords: 3' UTR/fem-3/mog/post-transcriptional control/RNA

\section{Introduction}

Sequence elements in the $3^{\prime}$ untranslated region (UTR) often regulate the stability, translation or localization of mRNAs (reviewed in Singer, 1993; Beelman and Parker, 1995; Curtis et al., 1995; Wickens et al., 1996, 1997). Although regulatory proteins have been identified that bind specifically to such cis elements (Legagneux et al., 1992; Murata and Wharton, 1995; Dubnau and Struhl, 1996; Smibert et al., 1996; Wang et al., 1996; Deshler et al., 1997; Kelley et al., 1997; Ostareck et al., 1997; Webster et al., 1997; Zhang et al., 1997), key questions remain unanswered. For example, by what mechanism does the RNA-binding protein regulate RNA activity? And how are regulatory processes modified during growth and development? To begin to address these questions, we have taken a molecular genetic approach to identify and characterize factors required in trans for the $3^{\prime}$ UTRmediated regulation of $\mathrm{fem}-3$, a sex-determining gene in Caenorhabditis elegans. This genetic strategy is designed to identify both regulators of the post-transcriptional machinery and components of the machinery itself.

Caenorhabditis elegans can develop either as a male or self-fertile hermaphrodite (female that briefly makes sperm), depending on its ratio of $\mathrm{X}$ chromosomes to sets of autosomes, the X/A ratio (reviewed in Kuwabara and Kimble, 1992; Meyer, 1997). The fem-3 gene is required for specification of male fates: $\mathrm{XX}$ and $\mathrm{X} 0$ animals, which would normally develop as hermaphrodites and males respectively, are both transformed into females in the absence of fem-3 activity (Figure 1A, top; Hodgkin, 1986; Barton et al., 1987). In contrast, hermaphrodites carrying dominant $\mathrm{fem}-3$ gain-of-function $(\mathrm{g} f$ ) alleles are masculinized in the germ line, producing excess sperm and no oocytes (Figure 1A, bottom; Barton et al., 1987). This is the Mog phenotype (masculinization of the germ line). Molecular characterization of $f e m-3(g f)$ alleles revealed a point mutation element, or PME, in the fem-3 $3^{\prime}$ UTR (Figure 1B; Ahringer and Kimble, 1991).

The PME appears to regulate $\mathrm{fem}-3$ activity posttranscriptionally. First, overexpression of an RNA consisting of the wild-type fem-3 $3^{\prime}$ UTR masculinizes the hermaphrodite germ line, but overexpression of a mutant fem-3 3' UTR with a defective PME does not have this effect (Ahringer and Kimble, 1991). A simple explanation is that the excess fem-3 3' UTR titrates a post-transcriptional repressor and thereby deregulates endogenous $\mathrm{fem}^{-3}$ RNA. Secondly, a cytoplasmic RNA-binding protein, called FBF (for fem-3 binding factor), is required for the switch from spermatogenesis to oogenesis (Zhang et al., 1997). FBF binds RNAs that contain a wild-type PME, but does not bind RNAs with a mutant PME. We hypothesize that fem-3 acts early in germ-line development to direct spermatogenesis and subsequently is repressed by a 3' UTR-mediated control to permit oogenesis.

Genes required in trans for the $3^{\prime}$ UTR-mediated repression of $\mathrm{fem}^{-3}$ are expected to have a loss-of-function ( $(f)$ Mog phenotype similar to that of the $f e m-3(g f)$ alleles. Mutations in six genes, mog-1-mog-6, satisfy this criterion (Graham and Kimble, 1993; Graham et al., 1993); in addition, animals lacking FBF activity as a result of RNAmediated interference have a Mog phenotype (Zhang et al., 1997). Epistasis analyses have placed all six mog genes and FBF upstream of the $\mathrm{fem}$ genes, consistent with their participation in fem-3 repression (Graham and Kimble, 1993; Graham et al., 1993; Zhang et al., 1997).

In this paper, we demonstrate that the fem-3 3 ' UTR confers PME-dependent repression of a reporter gene in vivo. Because the reporter assay was established in 
somatic tissues, we conclude that the machinery required for the post-transcriptional repression of fem-3 is present in somatic tissues as well as in the germ line. In support of this conclusion, we report a PME-dependent RNAbinding activity in somatic tissues that is possibly distinct from FBF. Finally, we show that each of six genes, $m o g-1-\operatorname{mog}-6$, is required for $3^{\prime}$ UTR-mediated repression.

\section{A}

fem-3 (If)- $\mathrm{XX}$ and $\mathrm{X} 0$ animals

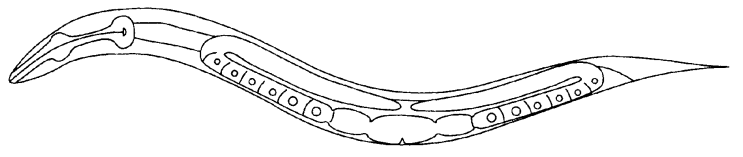

fem-3 (gf)- XX animals

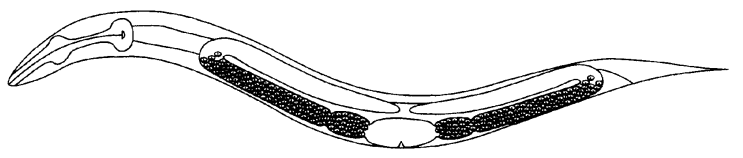

B

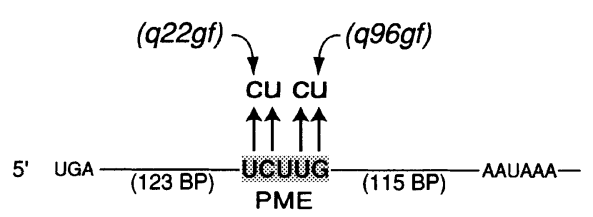

Fig. 1. The fem-3 sex-determining gene specifies male fates in both somatic and germ line tissues. (A) fem-3 mutant phenotypes. Above, both $\mathrm{XX}$ and $\mathrm{X} 0$ adults carrying a fem- 3 loss-of-function $(l f)$ mutation develop as females (Hodgkin, 1986). Below, XX adults carrying a fem-3 gain-of-function $(\mathrm{g} f)$ mutation have a masculinized germ line and therefore make only sperm (Barton et al., 1987). Anterior is left, dorsal is up. (B) The $f e m-3(g f)$ mutations carry point mutations within a five base nucleotide (nt) sequence of the fem-3 3' UTR. PME sequence shown within the $3^{\prime}$ UTR (thin line). Number of nucleotides found between stop codon and PME and between PME and AAUAAA are indicated in parentheses. $f e m-3(g f)$ nt changes are indicated by arrows (Ahringer, 1991; Ahringer and Kimble, 1991). Phenotypically, the weakest and strongest $f e m-3(g f)$ point mutations are $q 22 g f$ and q96gf (Barton et al., 1987).

Fig. 2. Regulation of reporter expression by the fem-3 3' UTR. (A) The lac $Z$ reporter construct consists of a heat shock promoter fused to a 5' UTR containing a synthetic intron (HSP, striped rectangle), lac $Z$ coding sequence fused to an SV40 nuclear localization signal (lacZ, white rectangle), a wild-type or mutant fem-3 3' UTR (thick black line) plus fem-3 $3^{\prime}$ flanking genomic sequence (light grey line). Relevant restriction sites used to determine integrity of transgenic lines and copy number of integrated transgenes are indicated (see Materials and methods). The 3' UTR portion of each construct is enlarged and the PME sequence indicated. The point mutation of lacZ::fem-3( $q 96 \mathrm{gf})$ contains a $\mathrm{C}$ to $\mathrm{T}$ change (middle construct). lacZ::fem-3(del8) contains an $8 \mathrm{nt}$ deletion (bottom construct). (B) Nomarski micrographs showing the typical amount of $\mathrm{X}$-gal staining found after heat shock of integrated transgenic lines: qIs43 [lacZ::fem-3(+)] and qIs15 [lacZ::fem-3(q96 gf)] (see Table I). Anterior is left, dorsal is up. Arrow points to an intestinal nucleus. (C) Graph of results of a single experiment with qIs43 [lacZ::fem3(+)], qIs15 [lacZ::fem-3(q96 gf)] and qIs44 [lacZ::fem-3(del8)]. $n$, number of animals examined. Similar results were also found with at least two independently isolated transgenic lines carrying extrachromosomal arrays (see Table I).

\section{Results}

\section{The fem-3 3' UTR represses a lacZ reporter gene in vivo}

To ask whether the fem-3 3' UTR is sufficient for PMEmediated regulation, we developed a transgenic reporter assay by fusing a fem-3 $3^{\prime}$ UTR to a lacZ reporter gene. lacZ::fem-3(+) contains a wild-type fem-3 3' UTR, whereas lacZ::fem-3(q96 gf) contains a mutant fem-3 $3^{\prime}$ UTR with a single base change in the PME, and lacZ:: fem-3(del8) contains a mutant fem-3 3' UTR with an eight-nucleotide (nt) deletion, removing the PME (Figure 2A). Since transgenes do not express well in the germ

A
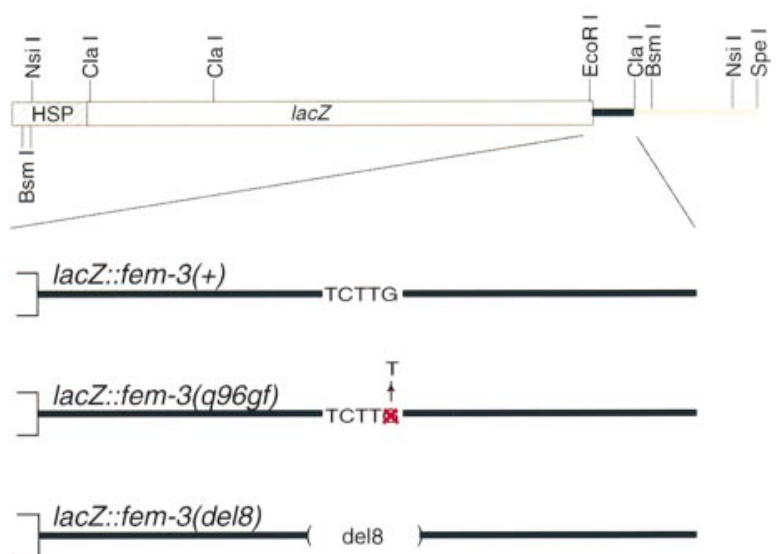

B
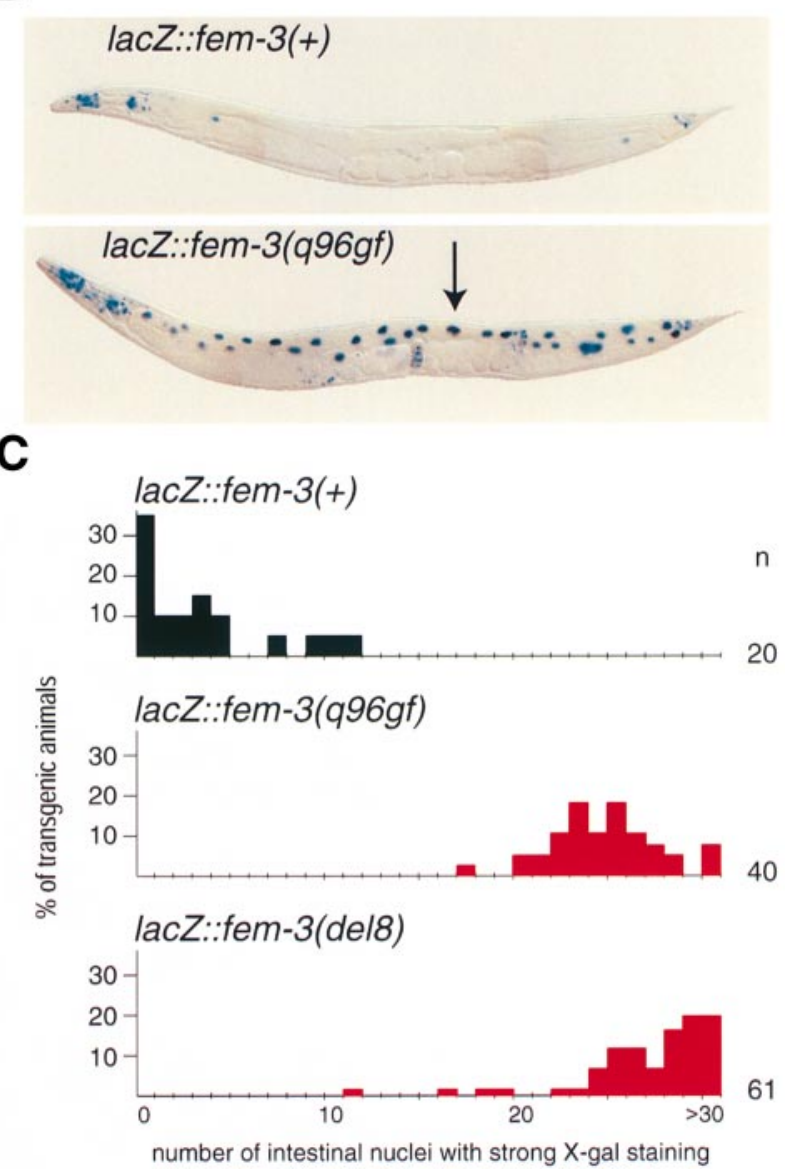


\begin{tabular}{|c|c|c|c|c|}
\hline Transgene name & Transgene type & Type of array & Transgene expression ${ }^{\mathrm{a}}$ & $\begin{array}{l}\text { No. of transgenes } \\
\text { per chromosome }\end{array}$ \\
\hline$q E x 212$ & lacZ::fem-3(+) & extrachromosomal & $+1-$ & - \\
\hline$q E x 213$ & lacZ: :fem-3(+) & extrachromosomal & $+1-$ & - \\
\hline qIs 43 & lacZ::fem-3(+) & integrated & $+1-$ & 4 \\
\hline qEx131 & lacZ::fem-3(q96gf) & extrachromosomal & ++++ & - \\
\hline$q E x 208$ & lacZ::fem-3(q96gf) & extrachromosomal & ++++ & - \\
\hline qIs 15 & lacZ::fem-3(q96gf) & integrated & ++++ & 3 \\
\hline$q E x 387$ & lacZ::fem-3(del8) & extrachromosomal & ++++ & - \\
\hline$q E x 388$ & lacZ::fem-3(del8) & extrachromosomal & ++++ & - \\
\hline qEx389 & lacZ::fem-3(del8) & extrachromosomal & ++++ & - \\
\hline qIs 44 & lacZ::fem-3(del8) & integrated & ++++ & 4 \\
\hline
\end{tabular}

${ }^{a}$ Transgene expression levels: $+/-(0-20 \%) ;+(20-40 \%) ;++(40-60 \%) ;+++(60-80 \%)$; and $++++(80-100 \%)$ of animals had $>20$ intestinal nuclei with strong X-gal staining. See Materials and methods for definition of strong X-gal staining.

${ }^{\mathrm{b}}$ Copy number was determined by Southern analysis of integrated lines using a radioactive probe that detected both the integrated transgene and endogenous $\mathrm{fem}^{-3}$ (see Materials and methods).

line of C.elegans and we did not know a priori which somatic tissues might contain fem-3 repressor activity, each lacZ::fem-3 construct was fused to the C.elegans hsp16 heat shock promoter. This promoter drives expression in various somatic tissues following heat shock (Stringham et al., 1992). Multiple lines containing extrachromosomal arrays of each lacZ::fem-3 transgene were generated and Southern blots were performed to confirm that the array carried full-length transgenes. An integrated line was also generated for each lacZ::fem-3 transgene and the copy number was determined (Table I; Materials and methods). $\beta$-galactosidase ( $\beta$-gal) activity in intestinal nuclei of adults was assayed using X-gal staining following heat shock. The intestine was assayed since it is easy to score.

Animals carrying lacZ::fem-3(+) expressed a low level of $\beta$-gal whereas animals carrying lacZ::fem-3(q96 gf) or lacZ::fem-3(del8) expressed a higher level of $\beta$-gal (Table $\mathrm{I}$; Figure $2 \mathrm{~B}$ and $\mathrm{C}$ ). Among the integrated lines, no lacZ::fem-3(+) animals exhibited strong X-gal staining in $\geqslant 20$ intestinal nuclei, in contrast to $92 \%$ of lac $Z:$ : fem-3(q96 gf) and 94\% of lacZ::fem-3(del8) animals (Figure 2B and C). We conclude that the $3^{\prime}$ UTR is sufficient to repress a heterologous reporter gene in vivo and that a wild-type PME is required for repression.

\section{The fem-3(gf) 3' UTR confers temperature- sensitive repression on a reporter in vivo}

The $f e m-3(g f)$ alleles are temperature sensitive: at $15^{\circ} \mathrm{C}$ most $f e m-3(g f)$ mutants make both sperm and oocytes, whereas at $25^{\circ} \mathrm{C}$ they make only sperm (Barton et al., 1987). Therefore, the $f e m-3(g f) 3^{\prime}$ UTR mediates repression at $15^{\circ} \mathrm{C}$, but not at $25^{\circ} \mathrm{C}$. To explore further the fem-3 3' UTR control, we asked whether reporter expression could be rendered temperature sensitive by a mutant fem-3(gf) 3' UTR. To this end, the coding region for green fluorescent protein (GFP) was fused either to a fem-3(q22 gf) or fem-3(q96 gf) mutant $3^{\prime}$ UTR or, as a control, to the fem-3(+) wild-type 3' UTR (Figure 3A); then each reporter was placed under the control of the lag-2 promoter, and multiple transgenic lines carrying extrachromosomal arrays were generated for each con- struct. The lag-2 promoter drives expression in the distal tip cells (DTC) of the somatic gonad (Henderson et al., 1994).

Transgenic animals were raised at 15 or $25^{\circ} \mathrm{C}$, and GFP expression was compared in animals possessing the same extrachromosomal array (Figure 3B). At $15^{\circ} \mathrm{C}$, GFP expression was low in GFP::fem-3(q22 gf) transgenic animals, but at $25^{\circ} \mathrm{C}$, GFP expression was high (Figure 3B, middle); the same was found for GFP::fem-3(q96 gf) transgenic animals (Figure 3B, right). However, GFP expression in GFP::fem-3(+)-bearing animals did not change substantially with temperature (Figure 3B, left) and it also did not change using another control transgene (lag-2::GFP fused to a wild-type unc-54 3' UTR) (data not shown). Therefore, point mutations in the $f e m-3(g f)$ 3' UTR reporter constructs render them temperature sensitive, consistent with the fact that the $f e m-3(g f)$ alleles are temperature sensitive. Furthermore, the temperature sensitivity of $f e m-3(g f)$ alleles is not germ-line specific.

\section{A PME-dependent fem-3 RNA-binding activity}

To identify an RNA-binding activity specific for a PME containing fem-3 3' UTR, we used a gel retardation assay. ${ }^{32} \mathrm{P}$-labelled RNA probes derived from the fem-3 3' UTR (Figure 4A) were incubated with crude extracts prepared from wild-type or mutant adults and then analysed by electrophoresis through a non-denaturing gel.

Figure 4B shows that a PME-dependent fem-3 RNAbinding activity is present in crude extracts of wild-type adults. Using RNAs containing either 35 or $81 \mathrm{nt}$ of the wild-type $f e m-3$ 3' UTR (including the PME), two complexes are formed in crude extract (Figure 4B, lane 2; and data not shown). In contrast, an RNA deleted for 8 nt spanning the PME forms no complex (Figure 4B, lane 6) and neither does an RNA with those 8 base pairs changed [chg8(81); Figure 4, legend; not shown]. To further demonstrate that these complexes are specific to a wild-type fem-3 3' UTR, we compared the ability of unlabelled wild-type and mutant RNAs to compete for complex formation with a labelled wild-type RNA. A 100 -fold excess of unlabelled RNA derived from the wildtype fem-3 3' UTR interferes with complex formation (Figure 4B, lane 3), whereas the same amount of an RNA 
A

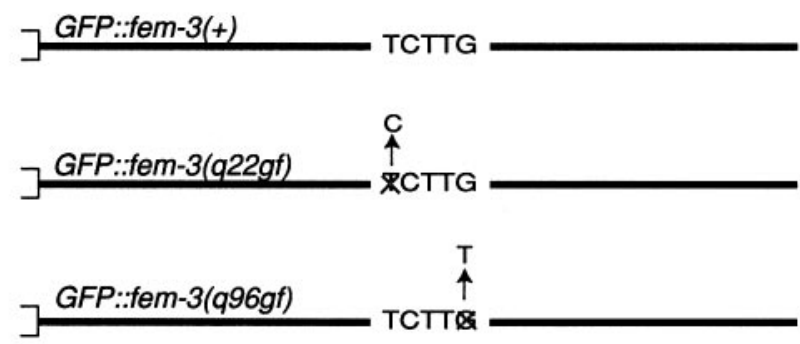

B
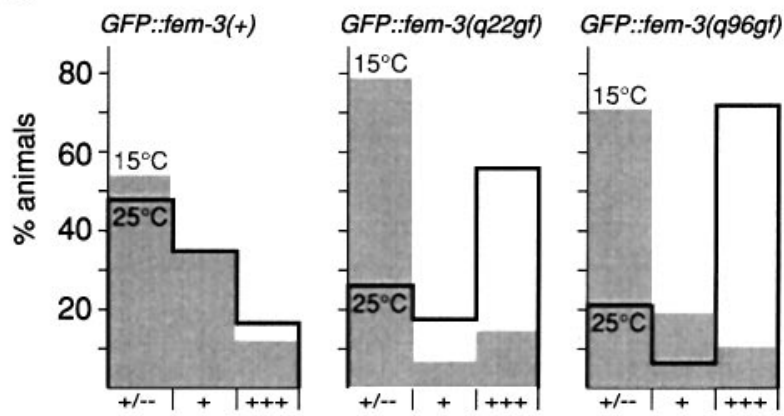

Fig. 3. Temperature-sensitive regulation of reporter expression by fem-3 (gf) 3' UTRs. (A) The fem-3 3' UTR portions of GFP::fem-3 reporter constructs. The entire construct is described in the text and detailed in Materials and methods. GFP::fem-3 reporters include a lag-2 promoter, GFP-coding sequence, a fem-3 3' UTR derived from fem-3(+), fem-3(q22 gf) or fem-3(q96 gf), and $766 \mathrm{nt}$ of fem-3 3' genomic flanking. The fem-3(q22 gf) and fem-3(q96 gf) mutations were selected for these experiments because they represent the weakest and strongest $f e m-3(g f)$ point mutants respectively (Barton et al., 1987). Only the $3^{\prime}$ UTR is shown and each point mutation is indicated. (B) GFP expression is evaluated at both $15^{\circ} \mathrm{C}$ (grey line) and $25^{\circ} \mathrm{C}$ (black line) in transgenic animals bearing extrachromosomal arrays with GFP::fem-3(+) (left), GFP::fem-3(q22 gf) (middle), and GFP::fem-3(q96 gf) (right). Each graph represents the combined data of four [GFP::fem-3(+)], five [GFP::fem-3(q96 gf)] or six [GFP:: fem-3(q22 gf $)]$ independently isolated transgenic lines. For GFP:: fem-3(+), 89 and 91 DTCs (two per animal) were scored at 15 and $25^{\circ} \mathrm{C}$, respectively; for GFP::fem-3(q22 gf), 89 and 100 DTCs were scored at 15 and $25^{\circ} \mathrm{C}$, respectively; for GFP::fem-3(q96 gf), 106 and 108 DTCs were scored at 15 and $25^{\circ} \mathrm{C}$, respectively. +++ , bright fluorescence; + , faint fluorescence; $+/-$, little or no fluorescence (see Materials and methods for further explanation of scoring).

with a mutant PME [chg8(81)] sequence does not compete (Figure 4B, lane 4) and an RNA bearing a point mutation competes more poorly than wild-type (data not shown).

To determine whether this PME-dependent fem-3 RNAbinding factor is present in somatic tissues, crude extracts were prepared from $g l p-1$ or $g l p-4$ mutants, which possess few germ cells (Austin and Kimble, 1987; Beanan and Strome, 1992). We found that complexes formed with extracts prepared from either wild-type animals that possess a full germ line or mutants that lack a germ line ( $g l p-1$ and $g l p-4$ ) (Figure 4C, compare lane 2 with lanes 3 and 4). The complexes are PME-specific since their formation is prevented by excess unlabelled wild-type RNA, but not by excess RNA lacking a PME (data not shown). We conclude that the somatic tissues possess a PME-dependent fem-3 RNA-binding activity. The simplest interpretation is that at least two PME-dependent RNAbinding proteins exist: FBF, which is germ-line specific
A

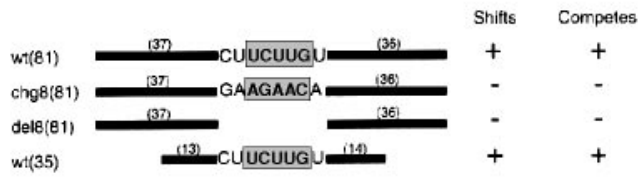

B

C

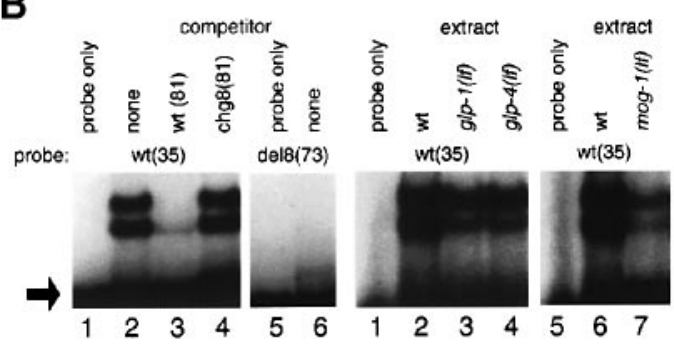

Fig. 4. Gel-shift assay using a fem-3 $3^{\prime}$ UTR RNA probe. (A) RNA probes were derived from the fem-3 $3^{\prime}$ UTR. Eight nt sequence including the PME (shaded) is shown, with number of flanking nt in parentheses. (B and C) Five fmoles of labelled RNA probe (see horizontal text above each gel) were incubated with $5 \mu \mathrm{g}$ of worm extract. An interaction between factor(s) from extract and probe is identified as a shift in migration of the RNA through a non-denaturing gel. Arrow signifies free probe. Where indicated, $500 \mathrm{fmol}$ of unlabelled competitor was included. (B) fem-3 RNA-binding activity requires a PME. All extracts were prepared from wild-type adults. The type of competitor RNA used in each case is indicated in vertical text. The chg8 RNA possesses GAAGAACA instead of CTTCTTGT in the PME region. (C) RNA-binding activity is present in somatic tissues and mog-1(q223) hermaphrodites. Mutant extracts were made from animals that lacked germ lines, $g l p-1(l f)$ and $g l p-4(l f)$ (see text for details), or mog-1(q223) mutants. The genotype of animals used to make extract is indicated in vertical text. The weak signal in lane 7 is probably due to the limited sample size [the extract was made from 700 hand-picked mog-1(q223) homozygotes].

(Zhang et al., 1997), and a distinct activity, which occurs in somatic tissues.

\section{The mog genes are required for fem-3 3' UTR-mediated repression}

Six mog genes encode candidate negative regulators of fem-3 (Graham and Kimble, 1993; Graham et al., 1993). To determine whether mog-1-mog-6 are required for the $3^{\prime}$ UTR-mediated repression of $f e m-3$, we examined expression of lacZ::fem-3(+) in mog mutants. For these experiments, we used $q I s 43$, an integrated line of lacZ::fem-3(+) (Figure 2 and Table I), and scored $\beta$-gal levels by X-gal staining in the self-progeny of parents homozygous for lacZ::fem-3(+) and heterozygous for the mutant (m) of interest. These progeny included nonMog hermaphrodites of genotype lacZ::fem-3(+); +/+ or lacZ::fem-3(+); $m /+$ and Mog animals of genotype lacZ::fem-3(+); $m / m$ ( $m=m o g-1,-4,-5,-6)$ (Figure 5A). $m o g-2(l f)$ and $m o g-3(l f)$ were assayed one generation later and only lacZ::fem-3(+); $\mathrm{m} / \mathrm{m}$ and lacZ::fem-3(+); +/+ were compared (see Materials and methods).

Non-Mog hermaphrodites carrying lacZ::fem-3(+) produced a low level of $\beta$-gal, whereas their lacZ::fem-3(+); $\mathrm{m} / \mathrm{m}$ Mog siblings produced a higher level of $\beta$-gal (Figure $5 \mathrm{~B}$ and C; Table II). Only $2 \%$ of non-Mog lacZ::fem$3(+)$ animals exhibited strong $\mathrm{X}$-gal staining in $>20$ intestinal nuclei. In contrast, 93\% (mog- 1$), 42 \%$ (mog- 2 ), $62 \%$ (mog-3), 95\% (mog-4), 86\% (mog-5) and 64\% (mog6) of lacZ::fem-3(+); mog-x $(x=1-6)$ mutants exhibited 
A Compare lacZ expression of WT and mutant siblings carrying an integrated lacZ::fem-3(+) transgene,

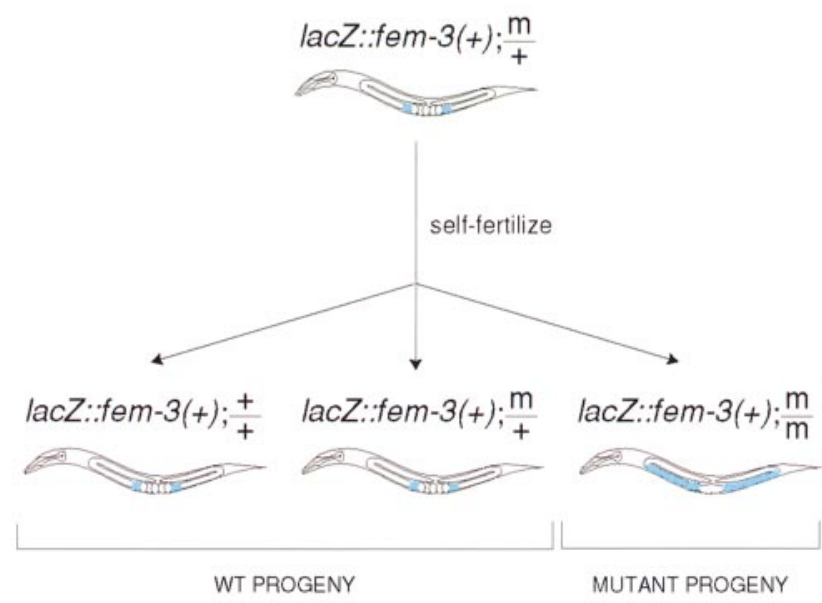

B

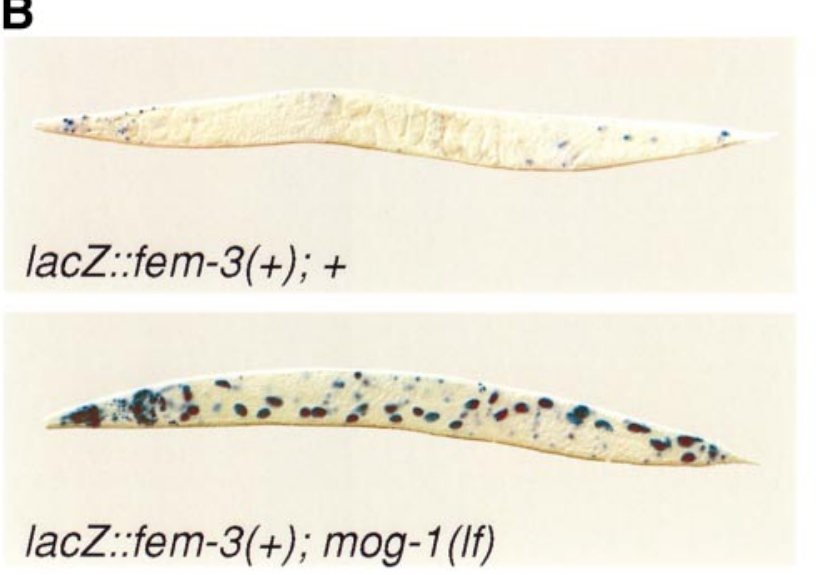

C
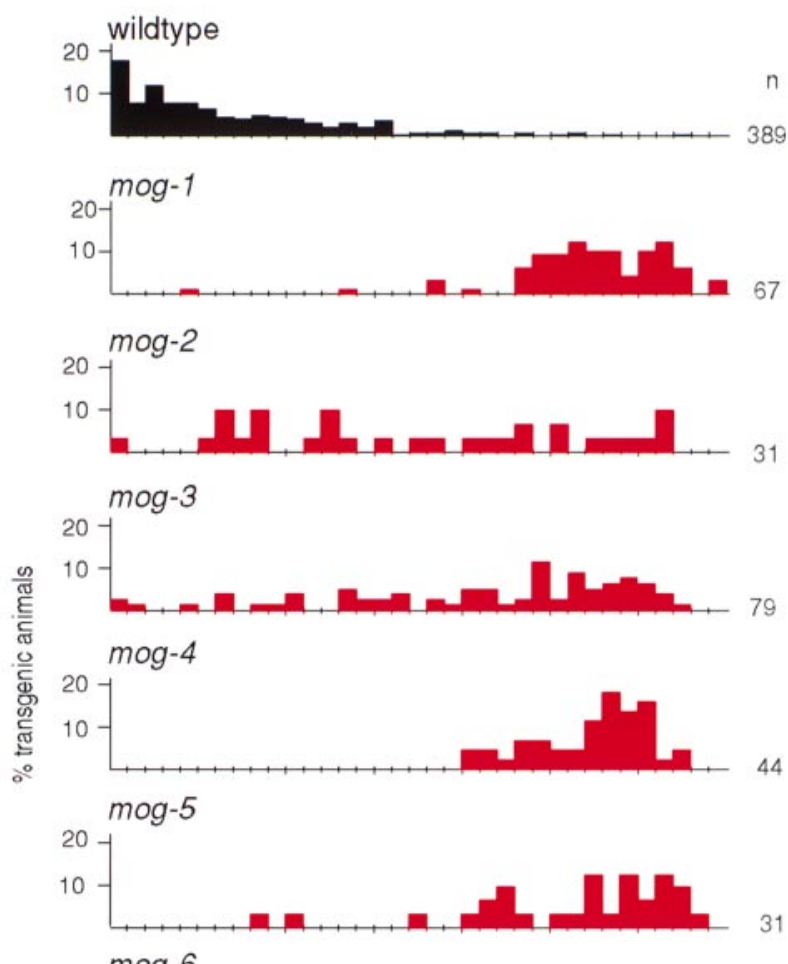

$\operatorname{mog}-6$

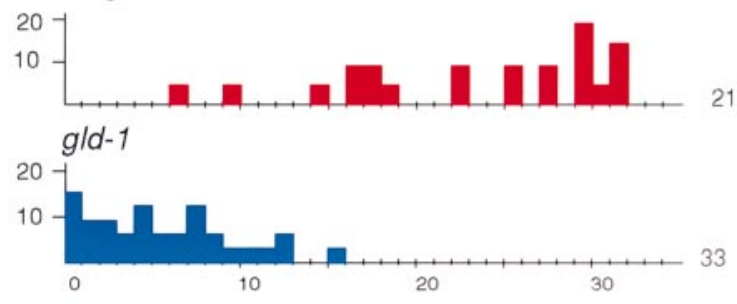

number of intestinal nuclei with strong $X$-gal staining

Fig. 5. Expression of lacZ::fem-3(+) in mog mutants. (A) The basic strategy used to examine qIs43 [lacZ::fem-3(+)] in various mutant backgrounds is outlined here (see Materials and methods for details and exceptions). Animals homozygous for lac $Z:$ fem-3(+) and heterozygous for the mutant $(\mathrm{m})$ of interest were self-fertilized. X-gal staining following heat shock of mutant [lacZ::fem-3(+); $\mathrm{m} / \mathrm{m}]$ and phenotypically wild-type [lacZ::fem$3(+) ;+/+$ and lacZ::fem-3(+); $\mathrm{m} /+$ ] siblings were compared. (B) Nomarski micrographs representing the typical amount of heat-induced X-gal staining seen with lacZ::fem-3(+) in a wild-type background (top) or mog-1 mutant background (bottom). Anterior is left, dorsal is up. (C) Data represented in graph form. Derepression is seen as a shift to the right in the mog graphs compared with the wild-type graph. The $y$-axis represents the percentage of animals, the $x$-axis represents the number of intestinal nuclei with strong X-gal staining per animal. The mutant background is labelled above each graph on the left. $n$ represents the number of animals examined. Each graph represents the combined results of at least two independent experiments. Control graph (black) represents a combination of all the wild-type animals examined in parallel with the mog and gld-1 mutant siblings.

strong X-gal staining in $>20$ intestinal nuclei. The weaker derepression of lacZ::fem-3(+) in $m o g-2(l f)$ and $m o g-3(l f)$ mutants is consistent with the fact that the $\operatorname{mog}-2(l f)$ and $m o g$-3(lf) alleles used in this assay are temperature sensitive and not likely to be null (Graham et al., 1993). The mog- 1 allele, however, is a molecular null (A.Puoti and J.Kimble, unpublished data), consistent with the stronger lacZ: :fem-3(+) derepression observed in mog-1 mutants.

As a preliminary step to determine whether any of the $m o g$ genes is required for the PME-dependent fem-3 RNAbinding activity detected by gel shift, we assayed binding activity in mog-1 (q223) mutants, a molecular null (A.Puoti and J.Kimble, unpublished data). Complex formation is indistinguishable between extracts prepared from wildtype animals (Figure 4C, lane 6) or mog- 1 nulls (Figure
4C, lane 7). In addition, complex formation in mog-1, as in wild-type, is specific since it is disrupted by coincubation with unlabelled wild-type fem-3 $3^{\prime}$ UTR RNA competitor [wt(81)], but not fem-3 RNA with a mutant PME [chg8(81)] (data not shown). This result is consistent with the finding that mog-1 fails to interact with the fem-3 3' UTR in a yeast 3-hybrid assay (A.Puoti and J.Kimble, unpublished data).

We conclude that each of the six mog genes is required for 3' UTR-mediated repression of fem-3 but that mog-1, at least, is not required for PME-dependent fem-3 RNAbinding activity. Whereas germ-line function is implied by the germ-line phenotype of mog mutants, this reporter assay provides in vivo evidence that the mog genes also function in the soma. Molecular evidence is also consistent with such a somatic function: mog- 1 RNA is detected in 


\begin{tabular}{|c|c|c|c|c|c|c|c|}
\hline \multirow[t]{2}{*}{ Line } & \multirow[t]{2}{*}{ Transgene type $^{\mathrm{a}}$} & \multirow{2}{*}{$\begin{array}{l}\text { Temperature } \\
\left({ }^{\circ} \mathrm{C}\right)\end{array}$} & \multicolumn{3}{|c|}{ Animals with strong $X$-gal staining $(\%)$ in ${ }^{b}$ : } & \multirow[t]{2}{*}{ Levels $^{\mathrm{c}}$} & \multirow[t]{2}{*}{ Number } \\
\hline & & & $<10$ & $10-20$ & $>20$ intestinal nuclei & & \\
\hline 1 & lacZ::fem-3(+) $\mathrm{d}^{\mathrm{d}}$ & 33 & 81 & 17 & 2 & $+1-$ & 556 \\
\hline 2 & lacZ::fem-3(+); mog-1 & 33 & 1 & 6 & 93 & ++++ & 67 \\
\hline 3 & lacZ::fem-3(+); mog-2 & 33 & 29 & 29 & 42 & ++ & 31 \\
\hline 4 & lacZ::fem-3(+); mog-3 & 33 & 15 & 23 & 62 & +++ & 79 \\
\hline 5 & lacZ::fem-3(+); mog-4 & 33 & 0 & 5 & 95 & ++++ & 44 \\
\hline 6 & lacZ::fem-3(+); mog-5 & 33 & 7 & 7 & 86 & ++++ & 31 \\
\hline 7 & lacZ::fem-3(+); mog-6 & 33 & 9 & 27 & 64 & +++ & 22 \\
\hline 8 & lacZ::fem-3(+); gld-1(q93) & 33 & 88 & 12 & 0 & $+1-$ & 33 \\
\hline 9 & lacZ::fem-3(+); fog-1 & 33 & 89 & 11 & 0 & $+1-$ & 100 \\
\hline 10 & lacZ::fem-3(+); glp-4 & 33 & 73 & 22 & 5 & $+1-$ & 37 \\
\hline 11 & lacZ::fem-3(+); unc-17 & 33 & 98 & 2 & 0 & $+1-$ & 48 \\
\hline 12 & lacZ::fem-3(+); tra-2 & 33 & 96 & 4 & 0 & $+/-$ & 48 \\
\hline 13 & lacZ::fem-3(q96gf) & 30 & 81 & 17 & 2 & $+1-$ & 47 \\
\hline 14 & lacZ::fem-3(q96gf); mog-1 & 30 & 86 & 14 & 0 & $+1-$ & 50 \\
\hline 15 & lacZ::fem-3(del8); dpy-19 & 30 & 82 & 4 & 14 & $+1-$ & 22 \\
\hline 16 & lacZ::fem-3(+); dpy-19 mog-1 & 30 & 95 & 5 & 0 & $+1-$ & 39 \\
\hline 17 & lacZ::tra-2(+) & 33 & 100 & 0 & 0 & $+1-$ & 219 \\
\hline 18 & lacZ::tra-2(+); mog-1 & 33 & 97 & 3 & 0 & $+1-$ & 111 \\
\hline
\end{tabular}

a $q I s 43[$ lacZ::fem-3(+)], qIs15 [lacZ::fem-3(q96)] and qIs44 [lacZ::fem-3(del8)] integrated transgenes were used in these experiments (see Table I). ${ }^{\mathrm{b}}$ See Materials and methods for definition of strong X-gal staining.

${ }^{\mathrm{c}}$ Transgene expression levels: $+/-(0-20 \%) ;+(20-40 \%) ;++(40-60 \%) ;+++(60-80 \%) ;$ and $++++(80-100 \%)$ of animals had $>20$ intestinal nuclei with strong X-gal staining.

${ }^{\mathrm{d}}$ Results represent the combined data from control experiments done in parallel with rows 2-12.

the soma and mog-1::GFP promoter fusion is expressed in somatic tissues, including the intestine (A.Puoti and J.Kimble, unpublished data). Expression in the intestine is consistent with the $3^{\prime}$ UTR-mediated repression of lacZ in that tissue.

\section{Other genes with mog-1-like mutant phenotypes do not derepress lacZ::fem-3(+)}

To determine whether derepression of lacZ::fem-3(+) is specific to the mog genes, we examined the expression of lacZ::fem-3(+) (qIs43) in other mutant backgrounds that share some of the phenotypic effects of mog mutants. The mog- 1 mutant phenotype is characterized by a masculinized hermaphrodite germ line, reduced germ-line proliferation and a slow growth defect (Graham and Kimble, 1993; A.Puoti and J.Kimble, unpublished data). To test whether derepression might be linked to one of these phenotypes instead of the mog mutant genes themselves, we examined lacZ::fem-3(+) in an unc-17(lf) background, which is a mutant with a slow growth defect (Rand and Russell, 1984), and in mutants with defective germ lines: fog-1(lf) feminizes the germ line (Barton and Kimble, 1990), glp-4(lf) reduces germ-line proliferation (Beanan and Strome, 1992), gld-1(q93) masculinizes the germ line (Mog phenotype) (Francis et al., 1995), and tra-2(b202 ts) transforms XX hermaphrodites into pseudomales (Hodgkin and Brenner, 1977). Furthermore, tra-2, like the mog genes and FBF, is positioned upstream of $f e m-3$ in a negative regulatory pathway (Hodgkin, 1986). To perform these experiments, we followed the protocol described in Figure 5A and in Material and methods.

Unlike our finding with the mog mutants, lacZ:: fem-3(+) remained repressed in these other mutant back- grounds. Thus, $0 \%$ ( $g l d-1), 0 \%$ (fog- 1 ), 5\% (glp-4), 0\% (tra-2) and $0 \%$ (unc-17) of mutants carrying lacZ:: $\mathrm{fem}-3(+)$ expressed a high level of $\beta$-gal in $>20$ intestinal nuclei when placed in the mutant background indicated in parentheses. These numbers are comparable with the $2 \%$ of lacZ::fem-3(+) wild-type control animals that produced a high level of $\beta$-gal in $>20$ intestinal nuclei (Table II, compare line 1 with lines $8-12$; for gld-1, Figure 5C).

We conclude that the derepression of lacZ::fem-3(+) observed in the mog mutant background does not occur due to the lack of a sperm/oocyte switch, the reduced germ-line proliferation or slow growth of mog mutants. Instead, we propose that the mog genes themselves are required for fem-3 $3^{\prime}$ UTR-mediated repression. In addition, because lacZ::fem-3(+) remains repressed in pseudomales [XX tra-2(lf) animals], we suggest that repressor activity is present in both hermaphrodites and males. Consistent with this result, lacZ::fem-3(+) expresses $\beta$-gal at a low level in X0 males (data not shown) and factor(s) from crude extracts prepared from X0 males also contain detectable fem-3 RNA-binding activity (Ahringer, 1991).

\section{mog-1-mediated repression requires a PME-containing fem-3 3' UTR}

To determine whether the mog genes derepress any mRNA regardless of sequence, we next assayed a different reporter transgene, lacZ::tra-2(+), in a mog-1 mutant background. lacZ::tra-2(+) contains the lacZ gene fused to a tra-2 $3^{\prime}$ UTR and is driven by a heat shock promoter (Goodwin et al., 1997). The tra-2 3' UTR contains a negativeacting regulatory element distinct from the fem-3 $3^{\prime}$ UTR 
A tem-3 is developmentally regulated to achieve the sperm/oocyte switch

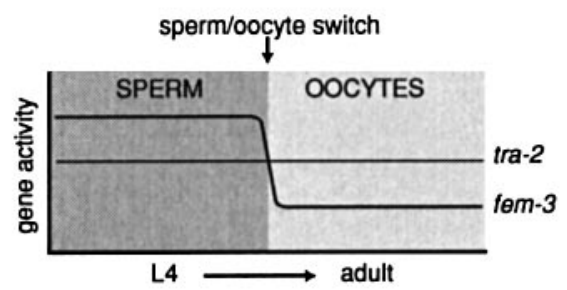

B tra-2 is developmentally regulated to achieve the sperm/oocyte switch

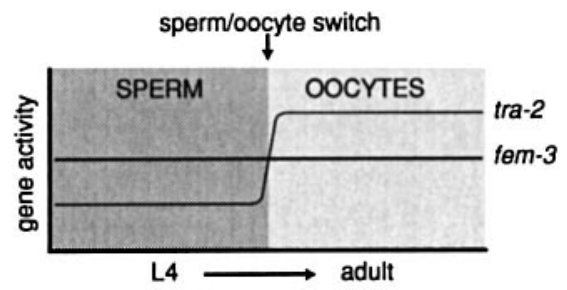

C fem-3 and tra-2 are both developmentally regulated to achieve the sperm/oocyte switch

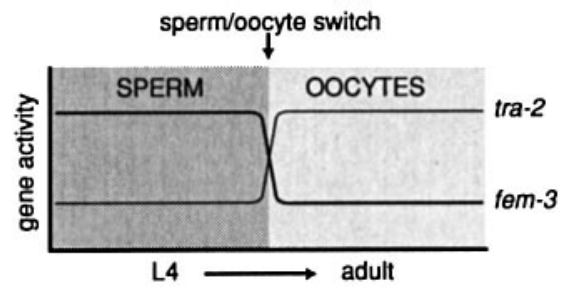

Fig. 6. Models for genetic regulation of the sperm/oocyte switch. All three models result in a high fem-3/tra-2 ratio early in germ-line development to make sperm and a low fem-3/tra-2 ratio later to make oocytes. (A) In the first model, the fem-3 repressor (e.g. FBF and/or the mog genes) is developmentally regulated: its activity is first low, resulting in a high relative level of fem-3 (thick line) and spermatogenesis, and then is increased to repress $\mathrm{fem}-3$ and switch to oogenesis. In this model, tra-2 activity (thin line) remains constant. (B) In the second model, the tra-2 repressor is developmentally regulated such that its initial activity is high, resulting in a low relative level of tra-2 (thin line) so spermatogenesis can occur, and then is decreased to derepress tra-2 and switch to oogenesis. In this model, fem-3 activity (thick line) is kept to a constant low level. (C) In the third model, both $\mathrm{fem}-3$ and tra-2 are developmentally regulated.

(Goodwin et al., 1993). We found that lacZ::tra-2(+) remained repressed in a mog- 1 mutant background (Table II, compare line 17 with line 18).

To test whether the PME itself mediates mog repression, we asked whether lacZ::fem-3(q96 gf) or lacZ::fem-3(del8) can become further derepressed in a mog-1 mutant background. If, on the one hand, the $q 96$ and del8 lesions do indeed abolish PME function, lacZ:: fem-3(q96 gf) and lacZ::fem-3(del8) should not become derepressed further in a mog- 1 mutant background if mog- 1 functions through the fem-3 PME. On the other hand, if mog-l functions through a cis-element independent of the PME, additional derepression of lacZ::fem-3(q96 gf) and lacZ::fem-3(del8) should occur. Heat shock was carried out at $30^{\circ} \mathrm{C}$ since lacZ::fem-3( $q 96 \mathrm{gf})$ and lacZ::fem-3(del8) already express a high level of $\beta$-gal when heat shocked at $33^{\circ} \mathrm{C}$. The hsp-16 promoter is less active at 30 than $33^{\circ} \mathrm{C}$ (Jones et al., 1989).

Neither lacZ::fem-3(q96 gf) nor lacZ::fem-3(del8) become derepressed further when placed in a mog- 1 mutant background (Table II, compare lines 13 and 14, and lines 15 and 16). Two per cent of lacZ::fem-3(q96 gf) animals express $\beta$-gal in $\geqslant 20$ intestinal nuclei, which is not substantially different from $0 \%$ of lacZ:: fem-3( $q 96 \mathrm{gf})$; mog-1(lf) animals. Furthermore, $14 \%$ of lacZ::fem-3(del8); $d p y-19(l f)$ animals express $\beta$-gal in 20 intestinal nuclei in comparison with $0 \%$ of lacZ::fem-3(del8); mog-1(lf) dpy19(lf) animals. If lacZ::fem-3(del8); mog-1(lf) dpy-19(lf) had been derepressed, a percentage $>14 \%$ would have been expected. Therefore, in both experiments, the mog mutant animals are not derepressed when compared with their wild-type counterparts.

We conclude that the mog genes act, either directly or indirectly, through the fem-3 $3^{\prime}$ UTR. Moreover, mog-1, and perhaps the other mog genes, appear to function through the PME itself. These results suggest that the mog genes do not regulate all mRNAs but may regulate only those with a specific regulatory element.

\section{Discussion}

Three major conclusions can be drawn from the results reported here: (i) the fem-3 3' UTR is sufficient to confer repression of a reporter gene in a PME-dependent manner; (ii) the trans-acting factors required for fem-3 3' UTR repression are ubiquitous (present in both soma and germ line, males and hermaphrodites); and (iii) repression by the fem-3 3' UTR requires the mog genes, mog-1-mog-6.

\section{A ubiquitous mechanism of post-transcriptional control}

The regulatory machinery that confers fem-3 3 ' UTR regulation appears to be ubiquitous. Its presence in the germ-line tissue is supported by the germ-line phenotypes of $f e m-3(g f)$ and $m o g$ mutants (Barton et al., 1987; Graham and Kimble, 1993; Graham et al., 1993), and by the germline specificity of FBF, a PME-dependent fem-3 RNAbinding protein required for the sperm/oocyte switch (Zhang et al., 1997). Its presence in somatic tissues is established by the fact that two distinct reporter transgenes show PME-dependent repression by the fem-3 3' UTR in the soma. First, a lacZ::fem-3(+) reporter is repressed in intestinal cells and secondly, a GFP::fem-3(+) reporter transgene is repressed in the distal tip cell of the somatic gonad. Although other somatic tissues were not scored quantitatively, the lacZ::fem-3(+) reporter appears to be repressed in other somatic tissues as well. In addition, a PME-dependent RNA-binding activity is present in extracts prepared from mutants lacking a germ line. Therefore, a specific RNA-binding activity, which is possibly distinct from FBF, is present in somatic tissues.

In addition to its presence in both germ line and somatic tissues, the fem-3 3' UTR regulatory machinery is found in both XX hermaphrodites and X0 males, as assayed using the lacZ::fem-3(+) reporter transgene. Consistent with this finding, an extract prepared from males contains fem-3 3' UTR-binding activity (Ahringer, 1991). Furthermore, whereas tra-l $(g f) \mathrm{X} 0$ single mutants develop as females, the somatic tissues of tra-1(gf); fem-3(gf) X0 double mutants are partially masculinized (Schedl et al., 1989). Therefore, repressor activity appears to be ubiquitous. 
The ubiquitous nature of the fem-3 3' UTR-mediated repressor activity suggests that this control mechanism is not likely to play a major role in somatic sex determination: neither mog nor fem-3(gf) mutants exhibit obvious sexual transformations of XX somatic tissues (Barton et al., 1987; Graham and Kimble, 1993; Graham et al., 1993), and X0 wild-type animals develop as males despite the presence of fem-3 3' UTR repressor activity. It is possible that somatic sex is regulated primarily by the $\mathrm{X}$ :A ratio controlling the major sex-determination pathway (reviewed in Meyer, 1997) and not by 3' UTR-mediated repression of $f e m-3$. The absence of somatic masculinization of $f e m-3(g f)$ or mog mutant XX animals may result from controls that restrict fem-3 RNA to the hermaphrodite germ line. Indeed, fem-3 RNA appears to be expressed primarily in germ-line tissues during post-embryonic development (Rosenquist and Kimble, 1988).

\section{fem-3 3' UTR regulation, the mog genes and the sperm/oocyte switch}

How might a ubiquitous regulatory mechanism achieve a fine-tuned fate decision such as the sperm/oocyte switch? We envision three possible models (Figure 6), all of which bring in the sex-determining gene, tra-2, because the sperm/oocyte decision depends on a balance between tra-2 and fem-3 activities (Barton et al., 1987). The tra-2 gene represses the fem genes (Hodgkin, 1986), and TRA-2 protein physically interacts with FEM-3 protein (A.Mehra, L.Heck, P.E.Kuwabara and A.M.Spence, personal communication). Of great importance to this paper, an increase in tra-2 activity relative to that of fem-3 promotes female development, whereas the converse, an increase in fem-3 activity relative to tra-2, leads to male development.

In the first model, the regulatory machinery that represses fem-3 (e.g. FBF/mog genes) is regulated developmentally. A temporary decrease in fem-3 repressor activity would result in a temporary increase in fem-3 activity and hence the transient production of sperm (Figure 6A). This model requires the tissue-specific regulation of a ubiquitous machinery. In the second model, fem-3 is continually kept at a low level and, at that low level, is efficiently repressed by TRA-2. By this scenario, tra-2 repression (Doniach, 1986; Schedl et al., 1989; Goodwin et al., 1993) is high early in development, releasing enough fem-3 for spermatogenesis (Figure 6B). A third model invokes developmental regulation of both $\mathrm{fem}-3$ and $\mathrm{tra}-2$ repressors to achieve the switch (Figure 6C). To distinguish among these models, the developmental regulation of the fem-3 and tra-2 regulators must be understood.

\section{The mog genes and the regulatory machinery controlling the fem-3 3' UTR}

Previous work showed that the mog genes are critical for the sperm/oocyte switch and that they possibly act genetically upstream of fem-1, fem-2, fem-3, fog- 1 and fog-3, five genes required for specification of the sperm fate (Graham and Kimble, 1993; Graham et al., 1993; Ellis and Kimble, 1995). In this paper, we show that the $m o g$ genes are essential for repression by the fem-3 $3^{\prime}$ UTR. The mog genes are therefore excellent candidates for encoding components of the regulatory machinery responsible for fem-3 3' UTR repression. The only other component of the fem-3 3' UTR regulatory machinery identified to date is FBF. FBF is a PME-dependent fem-3 RNA-binding activity that functions as a fem-3 repressor in the germ line and is essential for the sperm/oocyte switch (Zhang et al., 1997). The identity of the PMEdependent fem-3 RNA-binding activity in somatic tissues is not known. Either this somatic binding activity is distinct from the currently known FBF or previous experiments were not sufficiently sensitive to detect FBF in somatic tissues.

The functions of FBF and the mog genes are similar in several ways. On the one hand, both are required for fem-3 3' UTR regulation during the sperm/oocyte switch and for robust germ-line proliferation (Graham and Kimble, 1993; Graham et al., 1993; Zhang et al., 1997; A.Puoti and J.Kimble, unpublished data; this paper). On the other hand, FBF does not appear to be involved with other mog functions: FBF protein and function seems to be limited to the germ line as assayed by immunocytochemistry and RNA-mediated interference (RNAi) (Zhang et al., 1997), whereas the mog genes function in the soma as well as the germ line (this paper). Since RNAi is particularly powerful for knocking out maternal gene functions, the lack of an embryonic lethal phenotype in $f b f(R N A i)$ animals is striking given the strong maternal embryonic lethality of mog mutations (see below). We suggest that the mog genes function in both FBF-dependent and FBF-independent RNA regulatory events.

The molecular relationship between the mog genes and FBF for regulation of the fem-3 3' UTR is not clear. The $m o g-1$ gene encodes a DEAH-helicase (A.Puoti and J.Kimble, unpublished data), which possibly functions in RNA regulation. It is not yet known whether mog- 1 functions directly or indirectly with FBF to achieve the post-transcriptional repression of fem-3. Indeed, we cannot rule out the possibility that the mog gene products and FBF may act independently to regulate fem-3 RNA.

\section{The mog genes and regulatory functions distinct from sex determination}

The mog genes possibly regulate other RNAs and other processes in addition to fem-3 and the sperm/oocyte switch. For example, all mog genes are required maternally for embryogenesis (Graham and Kimble, 1993; Graham et al., 1993). Furthermore, mog-2-mog-6 mutants have a variety of partially penetrant somatic defects (Graham et al., 1993), and mog-1 is required for robust germ-line proliferation and a wild-type growth rate (A.Puoti and J.Kimble, unpublished data). Therefore, the mog genes function broadly in both germ line and somatic tissues and in both embryonic and post-embryonic processes.

The identity of the other RNAs regulated by the mog genes is not known. Such RNAs may or may not contain a PME regulatory element. For example, one might speculate that the mog genes are designed to act with FBF and other RNA binding proteins that recognize a PMElike element. Alternatively, the mog genes may encode a complex that is brought to specific RNAs by a variety of different RNA-binding proteins with distinct specificities. A precedent for this latter form of regulation is found among sequence-specific transcriptional regulators, which provide promoter specificity for co-regulators that regulate transcription more generally (e.g. the SWI/SNF complex, Pazin and Kadonaga, 1997; or groucho, Parkhurst, 1998). 


\section{Materials and methods}

\section{Strains}

In addition to wild-type animals, Bristol N2 (Brenner, 1974), the following mutant strains were used: $m o g-1(q 223) / d p y-19(e 1259$ ts $)$ unc69(e587) III [JK885], mog-1(q151)/dpy-19(e1259 ts) unc-69(e587) III [JK1167], mog-2(q75 ts) III; him-8(e1489) IV [JK1960], mog-3(q74 ts) III [JK784], mog-4(q233)/mnC1 [dpy-10(e128) unc-52(e444)] II [JK907], mog-5(q449)/unc-85(e1414) dpy-10(e128) II [JK1330], mog-6(q465)/ sqt-1(e1350) II; him-8(e1489) IV [JK1500], gld-1(q93)/dpy-5(e61) unc13(e51) I [JK648], unc-17(e113) IV [CB113], him-5(e1490) V [CB1490], dpy-19(e1259 ts) III [CB1259], dpy-19(e1259 ts) mog-1(q223) III/ eT1(III;V) [JK1380], tra-2(b202 ts) II [DH202], fog-1 (q253 ts) I [JK560]. Strains with extrachromosomal and integrated arrays are: $+/+; q E x 212$ [JK1939], +/+; qEx213 [JK1940], +/+; qIs43 [JK2421], +/+; qEx131 [JK1935], +/+; qEx208 [JK1948], qIs15 [JK1950], +/+; qEx389 [JK2546], +/+; qEx387 [JK2547], +/+; qEx388 [JK2548], qIs44 [JK2567]. qIs15, qIs43 and qIs44 are integrated arrays of $q E x 208$, $q E x 213$ and $q E x 389$, respectively. Table I lists the constructs used to make these arrays.

\section{Reporter constructs}

lacZ::fem-3 constructs were made by inserting a 1028 bp EcoRV-HindIII fragment from pJK164 [fem-3(+)] or pJK172 [fem-3(q96)] into pPD50.14 digested with StuI and SpeI. The 1028 bp EcoRV-HindIII fragment includes $262 \mathrm{nt}$ of the fem-3 3' UTR and $766 \mathrm{nt}$ of $3^{\prime}$ flanking genomic sequence. pPD50.14 (provided by Andrew Fire) contains the C.elegans heat shock promoter 16.41-2 (Stringham et al., 1992), a synthetic 5' UTR containing an intron, lacZ-coding region (targeted to the nucleus by the SV40 NLS) and the unc-54 $3^{\prime}$ UTR. The unc-54 $3^{\prime}$ UTR is replaced by the fem-3 genomic sequence. The $3^{\prime}$ UTR of lacZ:: fem-3(del8) transgene was made by ligation PCR (Ho et al., 1989) using the lacZ::fem-3(+) construct as template. The 3' UTR of lacZ:: fem-3(del8) was confirmed by sequencing. lacZ::tra-2(+) was constructed as described previously and contains the entire tra-2 $3^{\prime}$ UTR (Goodwin et al., 1997). GFP::fem-3(q22 gf) and GFP::fem-3(q96 gf) were made as follows: the 1028 bp EcoRV-HindIII fragment (described above) from pJK164 [fem-3(+)]. pJK165 [fem-3(q22)] or pJK172 [fem-3(q96)] was cloned into pOCUS (Novagen). This fragment was then cut from pOCUS using EcoRI and SpeI and cloned into the EcoRI to SpeI sites downstream of GFP in pPD95.81 (provided by Andrew Fire), a C.elegans transformation vector that encodes GFP. In addition, a $3.0 \mathrm{~kb}$ Bam HI fragment containing the lag-2 promoter (D.Gao and J.Kimble, unpublished data) was cloned into pPD95.81 digested with BamHI.

\section{Generation of transgenic animals}

Transgenic animals were generated as described previously (Mello and Fire, 1995). Each injection mix contained either $1-2 \mathrm{ng} / \mu \mathrm{l}$ of the $l a c Z$ reporter with $50 \mathrm{ng} / \mu \mathrm{l} \mathrm{pRF} 4$ or $5 \mathrm{ng} / \mu \mathrm{l}$ of the GFP reporter with $100 \mathrm{ng} / \mu \mathrm{l}$ pRF4. pRF4 contains the dominant roller marker, encoded by the rol6(su1006) allele. Extrachromosomal arrays were integrated into the genome by 4000 Rads of gamma irradiation. The integrity of the lacZ transgenes in each line (both extrachromosomal and integrated arrays) was examined by Southern analysis: genomic DNA from each line was digested with BsmI (except qIs15 and qIs42), NsiI and ClaI (Figure 2A). Only transgenic lines that contained the appropriate sized band following hybridization with a probe that recognizes lacZ-coding sequences were used for further analysis (Table I). The importance of Southern analyses of transgenic lines became evident when truncated transgenes with no [lacZ::fem-3(+)] or low [lacZ::fem-3(q96 gf) or lacZ::fem-3(del8)] levels of $X$-gal staining were found. In addition, Southern analysis of integrated lines was used to determine the copy number of each transgene per chromosome: genomic DNA prepared from each integrated line was digested with $N s i$ and probed with an EcoRI-SpeI fragment from the fem-3 3' UTR of lacZ::fem-3(+) (Figure 2A). This probe detects both transgene and endogenous fem-3. Only lines containing a comparable number of intact transgenes were used (Table I).

\section{Scoring reporter expression}

lacZ. Adults carrying lacZ::fem-3 reporter transgenes were heat shocked at 30 or $33^{\circ} \mathrm{C}$ for $2 \mathrm{~h}$ and then allowed to recover at $25^{\circ} \mathrm{C}$ for another $2 \mathrm{~h}$. X-gal staining was performed at $37^{\circ} \mathrm{C}$ overnight as described previously (Edgar, 1995). Following X-gal staining, animals were mounted onto slides and examined by DIC optics. If an intestinal nucleus was filled entirely with blue precipitate or partially with a dark blue precipitate, the staining was scored as 'strong'. The total number of intestinal nuclei with strong X-gal staining was counted for each animal and plotted on a graph. The level of transgene expression was also converted into a symbol: $+/-$ for $0-20 \%,+$ for $20-40 \%,++$ for $40-60 \%,+++$ for $60-80 \%$ and ++++ for $80-100 \%$ of animals with $>20$ intestinal nuclei with strong X-gal staining.

GFP. Worms carrying GFP::fem-3 reporter transgenes were grown either at 15 or $25^{\circ} \mathrm{C}$ and also examined as adults. Because the GFP lines were not assayed for copy number or transgene integrity, we did not compare GFP expression between lines, but instead compared GFP expression at different temperatures within the same line. A combination of DIC optics to find the distal tip cell (DTC) and fluorescein filter sets to detect fluorescence was used to score GFP expression. The intensity of GFP fluorescence was evaluated as follows: $+/-$ if GFP was either not seen or detected only faintly at $63 \times$ after locating the distal tip cell with DIC optics; + if GFP was difficult to see but could be detected without first locating the DTC by DIC optics; +++ if GFP was very bright and easily scored. Data were combined from four GFP::fem-3(+), five GFP::fem-3(q96 gf) or six GFP::fem-3(q22 gf) transgenic lines carrying extrachromosomal arrays. Lines were scored during the first four to six generations.

\section{Transgene expression in mutant backgrounds}

To assess expression of lacZ::fem-3(+) in most mutant (m) backgrounds, lacZ::fem-3(+); $m /+$ hermaphrodites were placed singly onto Petri plates and allowed to self-fertilize [at $20^{\circ} \mathrm{C}$ for $m o g-1,-4,-5$ and -6, gld -1 and $u n c-17$ or $25^{\circ} \mathrm{C}$ for $t r a-2(l f t s)$ ]. Their self-progeny include phenotypically wild-type hermaphrodites of genotype lacZ::fem-3(+); $+/+$ or lacZ::fem-3(+); $\mathrm{m} /+$ or mutants of genotype, lacZ::fem-3(+)3' UTR; $\mathrm{m} / \mathrm{m}$ (see Figure $5 \mathrm{~A}$ ). $1 \%$ of $\mathrm{gld}-1(q 93) /+$ animals are Mog (Francis et al., 1995); therefore a small percentage of these mutant animals was actually lacZ: :fem-3(+); gld-1(q93)/+. Wild-type and mutant siblings were heat shocked and stained in parallel. Recovery after heat shock was at $20^{\circ} \mathrm{C}$ for $m o g-1,-4,-5$ and -6, gld -1 and $u n c-17$ and at $25^{\circ} \mathrm{C}$ for tra-2. lac $Z$ expression was determined by counting the number of intestinal nuclei with strong X-gal staining as described above. Each experiment was carried out at least twice.

The procedure to assess expression of lacZ::fem-3(+) in mog-2, mog-3 and $g l p-4$ mutant backgrounds was carried out in the following way. Strains were made at $15^{\circ} \mathrm{C}$ and X-gal staining of lacZ::fem-3(+); $+/+$ and lacZ::fem-3(+) $3^{\prime}$ UTR; $\mathrm{m} / \mathrm{m}$ adults was compared following growth at $25^{\circ} \mathrm{C}$ from the second larval stage (L2). Assays were performed one generation later; therefore, $\beta$-gal levels of fertile and sterile 'cousins' were compared following heat shock and recovery.

To assess expression of lacZ::fem-3(del8) and lacZ::fem-3(q96 gf) in a mog-1 mutant background, the same procedure was followed except that recovery of lacZ::fem-3(q96 gf); mog-l(lf), lacZ::fem-3(q96 gf); mog-1(lf)/+ and lacZ::fem-3(q96 gf); +/+ was performed at $25^{\circ} \mathrm{C}$. In addition, heat shock of lacZ::fem-3(del8); dpy-19 mog-1 (Table II, line 15) and lacZ::fem-3(del8); dpy-19 (Table II, line 16) were not performed in parallel. Instead each was performed in parallel with the same control: lacZ::fem-3(del8); +/+. We justified comparing these two lines since lacZ::fem-3(del8); $+/+$ in each case produced similar amounts of $\mathrm{X}$-gal staining.

\section{DNA constructs for gel shift analysis}

The vector pBSKS II+ (Stratagene) was used for all clones. chg8 and del 8 mutations were generated by ligation PCR using the wild-type fem-3 3' UTR as template (technique described in Ho et al., 1989). The inserts for wt(230), del8(222), sgf(230) and chg8(230) are a ClaI-EcoRV fragment containing the entire fem-3 $3^{\prime}$ UTR. wt(81), wt(35), $\operatorname{sgf(}(35)$ chg8(81) and del8(73) were constructed by PCR using the above constructs as templates. All constructs were sequenced.

\section{Crude extracts for gel retardation assays}

Adults [wild-type N2, glp-1(q224ts), glp-4(bn2 ts) and mog-1(q223) animals] raised at $25^{\circ} \mathrm{C}$ were washed twice in $\mathrm{M} 9$ buffer and frozen in liquid nitrogen. Unlike $g l p-1(q 224 t s)$ and $g l p-4(b n 2 t s), m o g-1(q 223)$ is not temperature sensitive; therefore, extract was made from hand-picked homozygotes. An equal volume of extract buffer (10 mM HEPES pH 7.6, $10 \mathrm{mM} \mathrm{KCl}, 1.5 \mathrm{mM} \mathrm{MgCl}, 1.0 \mathrm{mM}$ EDTA, 5\% glycerol, $1.0 \mathrm{mM}$ DTT, $10 \mathrm{mM}$ benzamidine, $10 \mu \mathrm{g} / \mathrm{ml}$ PMSF, $10 \mu \mathrm{g} / \mathrm{ml}$ leupeptin) was mixed with the worm pellet and then dounced by hand until only empty carcasses remained $(30-50 \times)$. The homogenate was spun for $15 \mathrm{~min}$ at $4^{\circ} \mathrm{C}$ to remove debris, and aliquots were frozen in liquid nitrogen. 
Protein concentrations were generally $2-10 \mathrm{mg} / \mathrm{ml}$ as determined by Bradford assay (Pierce).

\section{RNA probes}

$\left[{ }^{32} \mathrm{P}\right]$ UTP labelled RNA, synthesized in vitro using T3 or T7 RNA polymerase was purified from a denaturing polyacrylamide gel. A trace amount of $\left[{ }^{32} \mathrm{P}\right] \mathrm{UTP}$ was added to reactions synthesizing unlabelled RNA for quantification. After synthesis, unlabelled RNA was phenol/ chloroform extracted, spun through Sephadex G-50 column to remove unincorporated nucleotides and counted by the Cerenkov method to measure $\left[{ }^{32} \mathrm{P}\right] \mathrm{UTP}$ incorporation. All RNAs were precipitated with glycogen and resuspended in DEPC-treated water.

\section{Gel shift reactions and electrophoresis}

The standard reaction contained $10 \mu \mathrm{l}$ of $10 \mathrm{mM}$ HEPES $\mathrm{pH} 7.6,40 \mathrm{mM}$ $\mathrm{KCl}, 1 \mathrm{mM}$ DTT, $5 \mathrm{mM} \mathrm{MgCl}, 5 \%$ glycerol, $100 \mu \mathrm{g} / \mathrm{ml}$ yeast tRNA, $2000 \mathrm{U}$ RNAsin (Promega) and $5 \mu \mathrm{g}$ of extract and $5 \mathrm{fmol}$ of labelled RNA (Pikielny and Rosbash, 1986). Where indicated, 500 fmol of unlabelled competitor was used. Generally, a mix of all components except RNA was made and then added to a mixture of probe and competitor RNAs. After incubation at room temperature for $10 \mathrm{~min}$, $2 \mu \mathrm{l}$ of either $10 \mathrm{mg} / \mathrm{ml}$ or $25 \mathrm{mg} / \mathrm{ml}$ heparin was added and the entire reaction loaded on a $4 \%$ acrylamide, $1.3 \%$ bis gel. The running buffer and the gel contained $0.5 \times \mathrm{TBE}$ and $5 \mathrm{mM} \mathrm{MgCl}$.

\section{Acknowledgements}

We are very grateful to Marv Wickens and Kathy Barton for critical reviews of early drafts of the manuscript. We also would like to acknowledge Alex Puoti for sharing unpublished data, and Alex Puoti and Finn-Hugo Markussen for helpful comments on later drafts. We would also like to thank Andrew Fire for providing pPD50.14 and pPD95.81 DNA constructs and Dali Gao for providing an unpublished lag-2 construct. M.G. was supported by a NIH Molecular Biosciences Training Grant. J.K. received funding from the NIH and NSF, and is an investigator of the Howard Hughes Medical Institute.

\section{References}

Ahringer,J. (1991) Post-transcriptional regulation of fem-3, a sexdetermining gene of C.elegans. Doctoral dissertation. University of Wisconsin-Madison, Madison, WI.

Ahringer,J. and Kimble,J. (1991) Control of the sperm-oocyte switch in Caenorhabditis elegans hermaphrodites by the fem-3 $3^{\prime}$ untranslated region. Nature, 349, 346-348.

Austin,J. and Kimble,J. (1987) $g l p-1$ is required in the germ line for regulation of the decision between mitosis and meiosis in C.elegans. Cell, 51, 589-599.

Barton,M.K. and Kimble,J. (1990) fog-1, a regulatory gene required for specification of spermatogenesis in the germ line of Caenorhabditis elegans. Genetics, 125, 29-39.

Barton,M.K., Schedl,T.B. and Kimble,J. (1987) Gain-of-function mutations of $f e m-3$, a sex-determination gene in Caenorhabditis elegans. Genetics, 115, 107-119.

Beanan,M.J. and Strome,S. (1992) Characterization of a germ-line proliferation mutation in C.elegans. Development, 116, 755-766.

Beelman,C.A. and Parker,R. (1995) Degradation of mRNA in eukaryotes. Cell, 81, 179-183.

Brenner,S. (1974) The genetics of Caenorhabditis elegans. Genetics, 77, $71-94$.

Curtis,D., Lehmann,R. and Zamore,P.D. (1995) Translational regulation and development. Cell, 81, 171-178.

Deshler,J.O., Highett,M.I. and Schnapp,B.J. (1997) Localization of Xenopus $\mathrm{Vg} 1 \mathrm{mRNA}$ by Vera protein and the endoplasmic reticulum. Science, 276, 1128-1131.

Doniach,T. (1986) Activity of the sex-determining gene tra-2 is modulated to allow spermatogenesis in the C.elegans hermaphrodite. Genetics, 114, 53-76.

Dubnau,J. and Struhl,G. (1996) RNA recognition and translational regulation by a homeodomain protein. Nature, 379, 694-699.

Edgar,L.G. (1995) Blastomere culture and identity. In Epstein,H.F. and Shakes,D.C. (eds), Caenorhabditis elegans: Modern Biological Analysis of an Organism. Vol. 48. Academic Press, New York, NY, pp. 303-321.

Ellis,R.E. and Kimble,J. (1995) The fog-3 gene and regulation of cell fate in the germ line of Caenorhabditis elegans. Genetics, 139, 561-577.

Francis,R., Barton,M.K., Kimble,J. and Schedl,T. (1995) gld-1, a tumor suppressor gene required for oocyte development in Caenorhabditis elegans. Genetics, 139, 579-606.

Goodwin,E.B., Okkema,P.G., Evans,T.C. and Kimble,J. (1993) Translational regulation of tra-2 by its $3^{\prime}$ untranslated region controls sexual identity in C.elegans. Cell, 75, 329-339.

Goodwin,E.B., Hofstra,K., Hurney,C.A., Mango,S. and Kimble,J. (1997) A genetic pathway for regulation of tra-2 translation. Development, 124, 749-758.

Graham,P.L. and Kimble,J. (1993) The mog-1 gene is required for the switch from spermatogenesis to oogenesis in Caenorhabditis elegans. Genetics, 133, 919-931.

Graham,P.L., Schedl,T. and Kimble,J.K. (1993) More mog genes that influence the switch from spermatogenesis to oogenesis in the hermaphrodite germ line of Caenorhabditis elegans. Dev. Genet., 14, 471-484.

Henderson,S.T., Gao,D., Lambie,E.J. and Kimble,J. (1994) lag-2 may encode a signaling ligand for the GLP-1 and LIN-12 receptors of C.elegans. Development, 120, 2913-2924.

Ho,S.N., Hunt,H.D., Horton,R.M., Pullen,J.K. and Pease,L.R. (1989) Site-directed mutagenesis by overlap extension using the polymerase chain reaction. Gene, $77,51-59$.

Hodgkin,J. (1986) Sex determination in the nematode C.elegans: analysis of tra-3 suppressors and characterization of fem genes. Genetics, 114, $15-52$.

Hodgkin,J. and Brenner,S. (1977) Mutations causing transformation of sexual phenotype in the nematode Caenorhabditis elegans. Genetics, 86, 275-287.

Jones,D., Dixon,D.K., Graham,R.W. and Candido,E.P.M. (1989) Differential regulation of closely related members of the $h s p 16$ gene family in Caenorhabditis elegans. DNA, 8, 481-490.

Kelley,R.L., Wang,J., Bell,L. and Kuroda,M. (1997) Sex lethal controls dosage compensation in Drosophila by a non-splicing mechanism. Nature, 387, 195-199.

Kuwabara,P.E. and Kimble,J. (1992) Molecular genetics of sex determination in C.elegans. Trends Genet., 8, 164-168.

Legagneux,V., Bouvet,P., Omolli,F., Chevalier,S. and Osborne,B.H. (1992) Identification of RNA-binding proteins specific to Xenopus Eg maternal mRNAs: association with the portion of Eg2 mRNA that promotes deadenylation in embryos. Development, 116, 1193-1202.

Mello,C. and Fire,A. (1995) DNA transformation. In Epstein,H.F. and Shakes,D.C. (eds), Caenorhabditis elegans: Modern Biological Analysis of an Organism. Vol. 48. Academic Press, New York, NY, pp. 452-480.

Meyer,B.J. (1997) Sex determination and X chromosome dosage compensation. In Riddle,D.L., Blumenthal,T., Meyer,B.J. and Priess,J.R. (eds), C.elegans II. Cold Spring Harbor Laboratory Press, Cold Spring Harbor, NY, pp. 209-240.

Murata,Y. and Wharton,R. (1995) Binding of Pumilio to maternal hunchback mRNA is required for posterior patterning in Drosophila embryos. Cell, 80, 747-756.

Ostareck,D.H., Ostareck-Lederer,A., Wilm,M., Thiele,B.J., Mann,M. and Hentze,M.W. (1997) mRNA silencing in erythroid differentiation: hnRNP K and hnRNP E1 regulate 15-lipoxygenase translation from the $3^{\prime}$ end. Cell, 89, 597-606.

Parkhurst,S.M. (1998) Groucho: making its Marx as a transcriptional co-repressor. Trends Genet., 14, 130-132.

Pazin,M.J. and Kadonaga,J.T. (1997) SWI2/SNF2 and related proteins: ATP-driven motors that disrupt protein-DNA interactions? Cell, 88 , 737-740.

Pikielny,C.W. and Rosbash,M. (1986) Specific small nuclear RNAs are associated with yeast spliceosomes. Cell, 45, 869-877.

Rand,J.B. and Russell,R.L. (1984) Choline acetyltransferase-deficient mutants of the nematode Caenorhabditis elegans. Genetics, 106, 227-248.

Rosenquist,T.A. and Kimble,J. (1988) Molecular cloning and transcript analysis of fem-3, a sex-determination gene in Caenorhabditis elegans. Genes Dev., 2, 606-616.

Schedl,T. and Kimble,J. (1988) fog-2, a germ-line-specific sex determination gene required for hermaphrodite spermatogenesis in Caenorhabditis elegans. Genetics, 119, 43-61.

Schedl,T., Graham,P.L., Barton,M.K. and Kimble,J. (1989) Analysis of the role of tra-1 in germ line sex determination in the nematode Caenorhabditis elegans. Genetics, 123, 755-769. 
Singer,R. (1993) RNA zipcodes for cytoplasmic addresses. Curr. Biol., 3, 719-721.

Smibert,C., Wilson,J.E., Kerr,K. and Macdonald,P.M. (1996) smaug protein represses translation of unlocalized nanos mRNA in the Drosophila embryo. Genes Dev., 10, 2600-2609.

Stringham,E.G., Dixon,D.K., Jones,D. and Candido,E.P.M. (1992) Temporal and spatial expression patterns of the small heat shock (hsp 16) genes in transgenic Caenorhabditis elegans. Mol. Biol. Cell, $\mathbf{3}$, 221-233.

Wang,Z.-F., Whitfield,M., Ingledue,T., Dominski,A. and Marzluff,W. (1996) The protein that binds the 3' end of histone mRNA: a novel RNA binding protein required for histone pre-mRNA processing. Genes Dev., 10, 3028-3040.

Webster,P.J., Liang,L., Berg,C.A., Lasko,P. and Macdonald,P.M. (1997) Translational repressor bruno plays multiple roles in development and is widely conserved. Genes Dev., 11, 2510-2521.

Wickens,M., Kimble,J. and Strickland,S. (1996) Translational control of developmental decisions. In Hershey,J., Mathews,M. and Sonenberg,N. (eds), Translational Control. Cold Spring Harbor Laboratory Press, Cold Spring Harbor, NY, pp. 411-450.

Wickens,M., Anderson,P. and Jackson,R. (1997) Life and death in the cytoplasm: messages from the $3^{\prime}$ end. Curr. Opin. Genet. Dev., 7, 220-232.

Zhang,B., Gallegos,M., Puoti,A., Durkin,E., Fields,S., Kimble,J. and Wickens,M.P. (1997) A conserved RNA-binding protein that regulates sexual fates in the C.elegans hermaphrodite germ line. Nature, 390, $477-484$.

Received July 21, 1998; revised and accepted September 7, 1998 